Recebido em 15/03/2018. Aprovado em 25/05/2018. Avaliado pelo sistema double blind peer review. Publicado conforme normas da ABNT. http://dx.doi.org/10.22279/navus.2019.v9n1.p21-36.741

\title{
Avaliação de desempenho pelo EVA: estudo de caso em uma construtora de pequeno porte
}

Paula Nayara Costa Mestranda em Administração. Centro Federal de Educação Tecnológica de Minas Gerais (CEFET-MG) - Brasil. paulanayara1989@gmail.com

João Eduardo Ribeiro Mestrando em Administração. Centro Federal de Educação Tecnológica de Minas Gerais (CEFFtMG) - Brasil. joaoribeiro.cco@gmail.com

Lilian Marques Nagem Byrro Mestra em Administração. Centro Federal de Educação Tecnológica de Minas Gerais (CEFET-MG) Brasil. lilianbyrro@dcsa.cefetmg.br

Claudia Faria Maciel Mestranda em Administração. Centro Federal de Educação Tecnológica de Minas Gerais (CEFET-MG) - Brasil. cfariam@gmail.com

\section{RESUMO}

A análise de investimentos busca a avaliação e a seleção de oportunidades que darão à empresa um retorno econômico coerente com suas metas. As empresas, de forma a se manterem competitivas no mercado, precisam selecionar projetos relevantes que apresentarão retornos satisfatórios, condizentes com seus investimentos de capital. Para tanto, o aperfeiçoamento das ferramentas gerenciais da empresa torna-se apropriado, em prol de melhorar a escolha de novos empreendimentos. Dessa maneira, o objetivo desse trabalho foi verificar se a utilização da metodologia Valor Econômico Adicionado (EVA) na análise e precificação de projetos agrega informações e conhecimentos que não seriam alcançados por uma empresa de pequeno porte, com as metodologias utilizadas por ela atualmente. Com esse intuito, foi realizado um estudo de caso descritivo em uma empresa que realiza projetos públicos na área de construção civil, chamada Fator Construções. Ao analisar um projeto que foi executado pela empresa em questão, denominado Projeto $\mathrm{A}$, constatou-se que o custo do capital próprio foi relevante, quando calculado pelo atual método de análise utilizado pela empresa. Porém, quando se calcula o valor presente dos EVAs mensais, é observado que esse projeto não agrega valor à empresa. Com a utilização do EVA, o resultado muda inteiramente, demonstrando a importância de se considerar o real custo de capital na precificação e análise de projetos. A análise do presente estudo evidenciou a sensibilidade do resultado do projeto em relação ao custo do capital próprio.

Palavras-chave: EVA. Valor econômico adicionado. Capital asset pricing model. Criação de valor.

\section{EVA performance evaluation: case study at a small-scale construction company}

\begin{abstract}
The investment analysis seeks to evaluate the selection of opportunities that will provide the company an economic return consistent with its goals. The companies, in order to remain competitive in the market, need to select relevant projects that will present satisfactory returns, consistent with their capital investments. Therefore, the improvement of the company's management tools is appropriate, in order to improve the choice of new enterprises. The aim of this study was to verify if the use of the Economic Value Added (EVA) methodology in the analysis and pricing of projects adds information to a small firm that uses traditional measures of accounting profit. For that purpose, a descriptive case study was carried out in a firm in the civil construction sector, named Fator Construções. By analyzing a project that was executed by the firm, denominated Project $A$, it was found that the cost of equity was relevant, when calculated by the current method of analysis already used by the firm. However, when calculating the current value of the monthly EVAs, it possible to observe that the project does not add value to the firm. The research points that with the use of EVA, the result changes completely, demonstrating the importance of considering the real cost of capital in the pricing and analysis of projects. Lastly, the analysis showed the sensitivity of the project's result in relation to the cost of equity.
\end{abstract}

Keywords: EVA. Economic value added. Capital asset pricing model. Value creation. 


\section{INTRODUÇÃO}

Dadas as crescentes exigências de alta eficiência e a busca por resultados positivos, as empresas têmse empenhado continuamente em medir e aumentar seu desempenho com o intuito de proporcionar aos seus sócios e investidores melhores retornos. Uma das medidas que pode ser adotada pelas empresas é a análise de investimento, que busca a identificação, análise e seleção de oportunidades de investimento que lhes darão um retorno econômico coerente com suas metas. 0 processo envolve, assim, uma inter-relação econômica consciente entre a exposição a condições adversas potenciais e a rentabilidade esperada do investimento (LAPONNI, 2007). 0 gestor responsável precisa estar consciente do risco e da rentabilidade dos investimentos ou projetos que se encontram disponíveis para que ele consiga escolher dentre esses o que melhor atende as expectativas de seus clientes.

O planejamento financeiro auxilia as empresas a alcançar a eficiência desejada e diminui a possibilidade de falência. Para Marion (2009), a falta de planejamento financeiro ou ausência total de fluxo de caixa e a previsão de fluxo de caixa é uma das principais razões de falência ou insucesso das empresas. Esse planejamento se torna substancial quando se trata de Micro e Pequenas Empresas (MPE). É fundamental que as MPE façam a administração dos seus recursos financeiros de forma eficiente e sistêmica, dada sua maior sensibilidade à falência, para que elas consigam permanecer no mercado e competir com as grandes empresas estabelecidas no mercado (SEBRAE, 2012).

Os controles financeiros de empresas que trabalham com projetos são, normalmente, feitos individualmente por projeto e por exercício contábil. Conforme afirma Kerzner (2011, p. 14), nas empresas orientadas a projetos, como no setor de construção ou aeroespacial, cada projeto é caracterizado "como um centro de custos separado tendo seus próprios demonstrativos de lucros e prejuízos". O lucro total da empresa compreenderia o somatório dos lucros dos projetos.

A empresa utilizada na análise do presente estudo é uma Empresa de Pequeno Porte (EPP), chamada Fator Construções, que existe há nove anos no mercado, e tem como atividade principal a execução de projetos públicos na área de construção civil. Seus principais clientes são os governos e municípios, por isso, a análise financeira dos projetos e a correta precificação são ainda mais importantes. Isso porque, no edital de licitação, o governo apresenta o preço máximo de execução do projeto e o vencedor do processo licitatório será aquele que apresentar menor preço global, ou seja, a empresa que apresentar um menor preço pelo projeto inteiro. A empresa que ganha a licitação se compromete a executar a obra pelo preço com o qual ela venceu, conforme fixado nos editais específicos. Sendo assim, se a empresa precificar a execução do projeto com um preço inferior aos seus custos totais de produção ela terá que arcar com o prejuízo, já que o preço não pode sofrer alterações unilaterais.

Além disso, de acordo com a Lei 8.666/1993, é exigida da empresa licitante uma garantia, quantia determinada em $5 \%$ do valor total da obra que fica em posse do tomador do serviço até a conclusão da obra, o que onera mais a empresa (BRASIL, 1993). Essa garantia acaba contribuindo para a limitação do número de projetos simultâneos executados pela empresa, pois a empresa necessita de maior volume de capital de giro.

A mensuração do retorno ou do valor que um projeto ou empresa entregam aos seus sócios é muito importante para que os investidores permaneçam com suas aplicações. Dessa forma, medir o valor agregado ou adicionado por uma empresa é tanto uma questão acadêmica, já que poderá ser reaplicado em outros estudos, como uma oportunidade para que a empresa analisada ou empresas pertencentes ao mesmo setor possam aperfeiçoar sua operação.

Para aumentar seus lucros em situações normais de restrições orçamentárias, empresas com o perfil similar ao apresentado acima precisam escolher criteriosamente seus projetos, focando naqueles que apresentarão maior retorno (KERZNER, 2011). Uma alternativa para a empresa seria o aperfeiçoamento de suas ferramentas gerenciais com o objetivo de melhorar a escolha de seus investimentos e projetos; a alternativa que o presente trabalho propõe é analisar o Valor Econômico Adicionado (EVA).

O EVA tem como objetivo principal indicar se a empresa está aumentando seu valor, pois a subtração do custo do capital próprio do lucro operacional permite que seja analisado o valor com o qual a empresa está remunerando o acionista e se essa quantia agrega ou não valor aos sócios. Para determinar o custo do capital 
próprio é usual optar pelo Capital Asset Pricing Model (CAPM), que tem o objetivo de determinar a taxa de retorno esperado para os ativos considerando a variação do seu preço de negociação na bolsa de valores.

Dessa forma, o objetivo desse estudo é verificar se a utilização da metodologia EVA na análise e precificação de projetos agrega informações e conhecimentos que não seriam alcançados pela empresa Fator Construções com as metodologias utilizadas pela empresa atualmente. Nesse sentido, o presente trabalho procurou responder ao seguinte questionamento: A utilização da metodologia EVA na análise e precificação de projeto agrega informações e conhecimentos que não seriam alcançados por meio de metodologias mais simples utilizadas atualmente pela empresa? Durante o tempo da realização da pesquisa procurou-se encontrar trabalhos brasileiros que analisassem o desempenho de MPEs utilizando a metodologia EVA, porém constatou-se que o assunto ainda é pouco abordado em trabalhos acadêmicos. Dada a grande representatividade desse tipo de empresa no mercado brasileiro, se torna de grande importância incentivar a pesquisa nessa área. Dado a sua relevância, o presente trabalho buscou ajudar a expandir a literatura sobre o tema e a incentivar o estudo e a aplicação dessa ferramenta pelas empresas brasileiras, principalmente pelas micro e pequenas empresas.

Este artigo está estruturado da seguinte forma: a seção 2 apresenta o referencial teórico, que delineia os modelos que serão utilizados no estudo. A seção 3 descreve os aspectos metodológicos. Na seção 4 são discutidos os resultados e suas respectivas análises, e, por fim, a seção 5 irá destacar as conclusões.

\section{FUNDAMENTAÇÃO TEÓRICA}

Neste capítulo são abordados os custos de capital e o Valor Econômico Adicionado (EVA).

\subsection{Custos de Capital}

O custo de capital, conforme Gitman (2010, p. 432), pode "ser considerado a taxa de retorno exigida pelos fornecedores de capital no mercado", ou seja, é a taxa mínima de retorno que a empresa precisa alcançar em seus projetos para manter seus investidores. As empresas são financiadas pelo capital próprio (proveniente dos sócios ou acionistas) e pelo capital de terceiros (que podem ser provenientes de empréstimos, financiamentos, títulos de dívidas, emissão de ações, entre outros). De acordo com Samanez (2007), em ambos os casos o gestor deve se preocupar com o retorno exigido pelos fornecedores de capital, pois este deve ser coerente com o retorno que a empresa pode auferir.

Conforme Assaf Neto e Lima (2011), o custo total de capital da empresa é determinado pelo custo de cada fonte de financiamento multiplicada pelo capital investido. Eles afirmam que "o custo de capital de terceiros é definido de acordo com os passivos onerosos identificados nos empréstimos e financiamentos mantidos pela empresa" (ASSAF NETO; LIMA, 2011, p. 498). De acordo com os autores, para que o custo de capital seja encontrado, basta fazer o somatório de to dos os empréstimos e financiamentos, cada multiplicado pela taxa correspondente de juros cobrada. Para a determinação do custo de capital próprio, foi usado o CAPM.

\subsubsection{Capital Asset Pricing Model (CAPM)}

Todo investimento possui risco. Uma parte substancial do risco de um investimento pode ser eliminada por meio da diversificação. Porém, nem todo o risco consegue ser eliminado pela diversificação e essa parcela que resta é denominada risco sistemático, inerente a todos ativos negociados no mercado. 0 CAPM é um modelo de precificação de ativos que tem como objetivo determinar a taxa de retorno esperada para os ativos com risco sistemático. Segundo Castro J r. e Famá (2002), o modelo é baseado em uma série de princípios, que são: os investidores são racionais, avessos ao risco e buscam maximizar a utilidade esperada de sua riqueza; os investidores são tomadores de preço; os investidores possuem expectativas homogêneas a respeito dos retornos dos ativos; existe um ativo livre de risco que permite aos investido res tomar emprestado ou emprestar sem limite de quantias; admite-se que toda informação relevante está simultaneamente 
disponível para todos os investidores do mercado; a concorrência é perfeita, não existindo impostos ou restrições.

Desenvolvido por Sharpe (1964), paralelamente com Lintner (1965), Mossin (1966) e Black, Jensen e Scholes (1972), o CAPM foi baseado no trabalho clássico de Markowitz (1952) sobre diversificação e teoria moderna de portfólio (MACHADO; MACHADO, 2014). Segundo o modelo, o custo de capital corresponde à taxa de rentabilidade exigida pelos investidores como compensação pelo risco adicional, risco de mercado, ao qual estão expostos. Conforme Bruni (2008), deve existir uma relação linear entre risco e retorno. A fórmula do CAPM é dada pela Equação (1):

$$
\left.E\left(R_{d}\right)=R_{f}+\beta_{d}\left[E\left(R_{m}\right)-R_{f}\right)\right]
$$

em que:

$\mathrm{E}\left(R_{d}\right)$ é a taxa de retorno esperado de capital;

$R_{f}$ é 0 ativo livre de risco;

$R_{d}$ é conhecido como beta ou prêmio de risco do ativo;

$\mathrm{E}\left(R_{m}\right)$ é a taxa de retorno do mercado.

A taxa de retorno de um ativo é superior ao ativo livre de risco por um prêmio pelo risco existente nesse ativo e esse prêmio varia conforme a variação do beta (GITMAN, 2010). Conforme Bruni (2008, p. 168), o prêmio pelo risco "deve representar o excesso de retorno que recompense os riscos corridos". E o prêmio pelo tempo seria a taxa livre de risco, ou seja, seria a taxa que o investidor receberia por "sacrificar o consumo hoje em prol de um maior consumo amanhã" (BRUNI, 2008, p.167). Bruni (2008), afirma que no Brasil a melhor representação da taxa livre de risco é a taxa média do Sistema Especial de Liquidação e Custódia (SELIC). Assaf Neto e Lima (2011), afirmam que é necessária uma correta estimação do CAPM para que as opções de investimento sejam analisadas e otimizadas, ou seja, a partir da mensuração do retorno ideal para cada investimento, considerando os seus riscos, é possível escolher o projeto que melhor o remunere.

\subsection{Valor Econômico Adicionado (EVA)}

O maior objetivo da administração financeira é o aumento da riqueza dos sócios (BRUNI, 2008). Existem diferentes enfoques com o objetivo de analisar a criação de valor, sendo o EVA uma abordagem adotada por diversas empresas de consultoria. Trata-se de um indicador desenvolvido e popularizado pela empresa de consultoria Stern Stewart. Seus desenvolvedores defendem que o método permite aos executivos avaliar com clareza se o capital empregado em determinado projeto ou empresa está sendo bem aplicado.

O método apresentado pelo EVA se propõe a melhorar a informação fornecida pelo lucro contábil, o que se dá por meio de um ajustamento contábil em que o custo de oportunidade do capital próprio é deduzido do lucro contábil. Se após esse procedimento o lucro ainda for positivo, a empresa agrega valor para os sócios, ou seja, aquele novo lucro ajustado é o valor agregado à empresa, é seu diferencial em relação a outro investimento do mercado. Se após reduzir o custo de oportunidade do lucro contábil o valor se apresentar como negativo, a empresa está destruindo valor e, caso o investidor optasse por investir no mercado, ele teria o custo de oportunidade como uma remuneração maior àquela oferecida pela empresa.

Samanez (2010, p. 368) afirma que "O EVA pode ser interpretado como o lucro operacional remanescente depois que se considera a remuneração mínima exigida pelos proprietários (credores e acionistas)", ou seja, como o valor criado pela empresa ou projeto. 0 autor também aponta que 0 valor presente dos EVAs representa justamente a criação de valor. Além do lucro, torna-se importante a comparação deste com o custo de oportunidade, que é o retorno que os sócios esperam pelo capital investido na operação (BRUNI, 2008).

A partir da comparação, entre o EVA e o custo de oportunidade é possível auferir se o projeto ou investimento agrega ou não valor aos acionistas. Bruni (2008) descreve a fórmula do EVA conforme a equação (2): 


\section{EVA = Lucro líquido - Custo de Oportunidade dos Capitais Próprios}

Segundo Bruni (2008), o lucro líquido é obtido após se deduzir o custo do capital de terceiros, apresentado sob a forma de juros ou despesa financeira. Como no cálculo do lucro líquido não se inclui o custo de oportunidade do capital próprio da empresa ele apresenta um valor superestimado. Sendo assim, o EVA propõe um ajuste no cálculo do lucro líquido, incorporando o custo de oportunidade do capital próprio.

O custo de oportunidade considerado no EVA corresponde a quanto o capital próprio da empresa renderia se fosse investido em uma aplicação financeira de longo prazo e com risco similar ao da empresa. 0 custo de oportunidade é a taxa de retorno requerida pelos sócios multiplicada pelo volume de recursos próprios. Um EVA positivo significa que, mesmo considerando a remuneração de todos os financiadores, terceiros e sócios, a empresa ainda conseguiu gerar um excedente de remuneração (BRUNI, 2008).

Portanto, o EVA fornece aos acionistas e gestores um importante indicador de desempenho, que os auxilia a comparar o valor agregado por diversos investimentos e a escolher os investimentos que melhor atendem às suas expectativas.

Alguns estudos nos últimos anos utilizaram o EVA como ferramenta de análise de criação de valor para empresas. Girão, Machado e Calado (2013) buscaram examinar o poder explicativo do EVA e de outros indicadores contábeis tradicionais, e comparar tais medidas em relação a seu poder explicativo da criação de riqueza para os acionistas. Os autores utilizaram como amostra todas as empresas que tiveram cotação na Bolsa de Valores de São Paulo, no período amostral de 2000 a 2010. Dessa forma, a metodologia utilizada para testar o conteúdo informacional do EVA e dos demais indicadores do estudo foi regressões em método dos mínimos quadrados ordinários empilhados (POLS). Além disso, os autores também utilizaram de dois modelos multivariados, em que um continha apenas os indicadores contábeis tradicionais, e o outro em que era acrescentado o EVA, de forma a testar a hipótese de que o EVA adiciona conteúdo informativo aos outros indicadores, por meio do teste de Wald. Ao final do estudo, foi possível concluir que o EVA não é mais relevante na avaliação de valor do que os indicadores tradicionais, no entanto, agregam conteúdo informativo a eles.

Bassan e Martins (2016) analisaram a geração de riqueza, utilizand o o EVA, de 17 empresas vencedoras do Prêmio Nacional da Qualidade (PQN) para os anos de 2000 a 2009. Os autores apontam que o uso do EVA torna-se um diferencial do trabalho perante aos demais, visto que muitos utilizam de metodologias de análise baseadas em medidas de desempenho financeiro, e não focadas na criação de valor para as empresas. A conclusão permite verificar a existência de evidências que as empresas da amostra melhoraram o seu EVA no período de pós-adoção do Modelo de Excelência em Gestão, e ao comparar tais empresas com outras do mesmo setor, é constatado que as empresas da amostra possuem um EVA superior no período de pós-adoção do modelo do prêmio.

Curadi et al. (2017) buscaram apresentar a ferramenta por meio de uma análise descritiva, bibliográfica e um estudo de caso, em que se realizou uma análise comparativa do uso do EVA com outros indicadores tradicionais de desempenho econômico. Os autores concluem que o EVA desponta como um indicador fundamental para medir a real lucratividade da empresa. Ainda declaram que a ferramenta fornece um panorama sobre investimentos para gestores e investidores que permite melhor auxiliar na tomada de decisões estratégicas num ambiente corporativo.

\section{ASPECTOS METODOLÓGICOS}

Este capítulo caracteriza a pesquisa, a empresa e a fase de coleta e análise de dados.

\subsection{Caracterização da Pesquisa}

Este estudo é de carácter descritivo e quantitativo. Cervo, Bervian e Silva (2007) afirmam que a pesquisa descritiva permite ao pesquisador uma visão analítica, pois observa, registra, analisa e correlaciona 
os fatos sem alterá-los. Conforme Rampazzo (2005), a análise descritiva consiste na descrição das características, propriedades e relações existentes na comunidade, grupo ou realidade pesquisada, ela favorece a clareza na formulação do problema e da hipótese como tentativa de solução. A pesquisa descritiva expõe as características de determinada situação ou fenômeno, estabelece relações entre as variáveis e define sua natureza, de acordo com Cervo, Bervian e Silva (2007, p. 49).

Quanto ao método de pesquisa, foi utilizado um estudo de caso, que de acordo com Yin (2005), é uma investigação empírica que compreende a lógica de planejar, coletar e analisar dados, podendo ser usado com diferentes objetivos, desde uma apresentação de um caso individual ou até conseguir inferir resultados para a população, ou seja, a partir das evidências obtidas pelo estudo de caso conseguir generalizar. Segundo o autor, o estudo de caso se caracteriza por descrever um evento ou caso de uma forma longitudinal. Essa metodologia nasceu da necessidade de transmitir na íntegra a complexidade de situações reais com as quais são confrontadas todos os dias. Trata-se de um estudo de profundidade de uma unidade de interesse, em que a análise precisa ser feita de forma detal hada e exaustiva, considerando as influências internas e externas.

\subsection{A Empresa}

Analisa-se neste trabalho a Fator Construções, uma Empresa de Pequeno Porte (EPP). Há nove anos no mercado, tem como atividade principal a execução de projetos públicos na área de construção civil. 0 escritório da empresa fica localizado na região metropolitana de Belo Horizonte, em Minas Gerais. Seu principal segmento de clientes exerce grande influência na empresa, pois há um grande número de exigências que precisam ser atendidas para que a empresa seja habilitada a participar dos processos licitatórios. 0 pagamento desse grupo de clientes é realizado por cheque administrativo ou depósito em conta corrente, o processo de recebimento é burocrático e o prazo pode chegar a até 90 dias, conforme relatado pelos sócios.

De acordo com o art. 56 da já citada lei, é obrigatório em todas as prefeituras a apresentação de alguma das garantias: caução em dinheiro, seguro-garantia ou fiança bancária. Segundo os sócios, a empresa utiliza com mais frequência o seguro-garantia, que tem seu valor máximo estipulado por lei em $5 \%$ do total da obra. A obrigatoriedade da garantia aliada a um capital de giro bastante limitado acaba por determinar o número de projetos que a empresa consegue executar simultaneamente. Devido a essa situação, a empresa analisada trabalha com um número de projetos pequeno, que nos últimos dois anos variaram entre quatro e cinco. Nesse cenário, o administrador vê no aperfeiçoamento financeiro uma oportunidade de crescimento para a empresa, pois acredita ser necessário avaliar os projetos a fim de se obter melhores resultados.

A elaboração de uma abordagem disciplinada de estimação de preço auxilia no desenvolvimento de um método que consiga elencar todos os insumos necessários para uma recomendação racional de preços, ou seja, como resultado o tomador de decisões terá uma base que 0 auxilie na determinação do preço. Além de possibilitar a documentação de vários fatores e premissas que podem ser utilizados como parâmetro em um momento posterior, contribuindo assim para o processo de aprendizagem (KERZNER, 2011).

As estimativas dos custos do projeto é uma etapa importante, pois são predefinidos os recursos que serão utilizados durante todo o projeto e seus custos, além de estabelecer uma base que será utilizada para comparar o estimado com o que foi efetivamente realizado, ou seja, ele estabelece diretrizes para a execução do projeto em relação aos custos dispendidos durante o projeto. Como mencionado anteriormente, para que uma empresa se mantenha lucrativa ao longo do tempo é fundamental que procure melhorar continuamente suas metodologias de precificação e de estimativas de custos (KERZNER, 2011).

Os projetos da construção civil têm como custos principais: mão de obra e matéria-prima. De acordo com a Secretaria de Estado de Transporte e Obras Públicas (SETOP), trinta e cinco por cento dos gastos de um projeto de construção civil são referentes à mão de obra direta e sessenta e cinco por cento são referentes à matéria-prima. Dentro do percentual de mão de obra já estão inclusos os custos com impostos trabalhistas.

Em cima do valor do projeto incide um percentual chamado Bonificação e Despesa Indireta (BDI) que é definido pela empresa, conforme o Acórdão 325/2007, esse percentual deve ser menor que 30\% (trinta por cento) do total do projeto. Esse percentual tem como objetivo cobrir os desembolsos referentes à administração central, riscos e eventuais, despesa financeira, impostos e lucro. 
O custo de manutenção da infraestrutura é denominado Administração Central e deve ser rateado para todos os projetos da empresa. Ele é composto por: pró-labore dos sócios, salário dos funcionários do escritório e despesas com luz, água, telefone, internet etc. Esse custo entra na composição do custo do projeto como um percentual do BDI.

O percentual de despesas financeiras é uma projeção do custo de capital que será necessário para executar a obra, esse valor é composto pelos valores que a empresa paga de juros, taxas etc. 0 valor destinado aos Riscos e Eventuais é um percentual para que a empresa possua uma provisão para possíveis contingências, possui o objetivo de cobrir eventos que onerem o projeto, mas não podem ser previstos.

O percentual de Impostos é definido pelo faturamento da empresa por meio do Simples Nacional. Atualmente, a empresa paga um percentual de $11,57 \%$ da receita bruta. O lucro do projeto é calculado como um percentual destinado aos sócios, caso a empresa consiga executar o projeto dentro do limite de custo planejado. Esse percentual gira em torno dos 5\%, percentual de lucro indicado como a média de lucro da engenharia de acordo com a SETOP.

\subsection{Coleta e Análise dos Dados}

Para o presente estudo, foram analisados os dados obtidos dos documentos contábeis e relatórios gerenciais da empresa para o período amostral de 2013 a 2014, com a pretensão de encontrar o EVA de um projeto. A análise permitiu montar o fluxo de caixa mensal do projeto e o saldo investido em cada período supracitado. 0 período foi escolhido por se tratar dos anos em que foi realizado o Projeto $A$, foco da análise do presente estudo. Além disso, foi realizada uma entrevista semiestruturada com os gestores/donos para melhor entendimento dos processos da empresa.

Para o cálculo do custo de capital de terceiros, foi realizado o somatório do produto dos saldos devedores com suas respectivas taxas efetivas de juros para que fosse encontrado o Custo Médio Ponderado do Capital (CMPC). A estrutura de capital da empresa não sofreu modificações significativas durante o perío do de execução do projeto analisado e por isso a pesquisa irá considerar o mesmo custo de capital de terceiros para todos os projetos.

Para determinar o custo do capital próprio, foi usado o CAPM. Foram selecionadas as empresas do setor de construção civil listadas na Bolsa de Valores de São Paulo (Bovespa), excluindo da amostra empresas que não tiveram movimento no período considerado. 0 risco sistemático (beta) de cada empresa foi calculado entre seus retornos mensais e os retornos mensais do Índice da Bolsa de Valores de São Paulo (Ibovespa) utilizando-se um período de 194 meses (novembro/1998 a dezembro/2014). Os dados sobre o preço das ações foram coletados pelo Yahoo Financeiro. Foi utilizado o preço de fechamento ajustado para dividendos e desdobramentos, do primeiro dia útil de cada mês, e as informações financeiras foram coletadas no próprio site das empresas.

A partir dos betas alavancados de cada empresa foi calculado o beta desalavancado, considerando a estrutura de capital individual. Com os betas desalavancados foi calculado o beta médio desalavancado do setor, retirando duas empresas que foram consideradas outliers. A última etapa no cálculo do beta foi alavancar o beta médio desalavancado considerando a estrutura de capital da empresa objeto do estudo de caso.

A fórmula para o cálculo dos betas desalavancados utilizada no trabalho foi similar à utilizada por Damodaram (1999, p.71), conforme a Equação (3):

$$
\beta_{u}=\beta_{1} /[1+D(1-t) / E]
$$

em que:

$\beta_{\mathrm{u}}$ é o beta alavancado;

$\beta_{1}$ é o beta desalavancado; 
D é o volume de dívidas que a empresa possui;

té a alíquota de IR e de contribuição social sobre o lucro;

Eé o patrimônio líquido.

Para alavancar de acordo com a estrutura de capital da empresa a equação apenas foi manipulada, ficando da seguinte forma:

$$
\beta_{\mathrm{L}}=\beta_{\mathrm{u}}[1+\mathrm{D}(1-\mathrm{t}) / \mathrm{E}]
$$

Diversas formas de estimativa do beta foram testadas, mas devido à crise de 2008 a bolsa teve um grande período de retornos negativos, por isso optou-se por considerar um período maior de tempo para que impacto na crise não enviesasse os resultados. Como ativo livre de risco, o trabalho adotou a média do rendimento da poupança no mesmo período usado para o cálculo do beta (novembro/1998 a dezembro/2014). Os dados foram coletados no site do Banco Central do Brasil sendo utilizados os rendimentos do primeiro dia útil de cada mês de execução do projeto.

De posse dos dados foi possível calcular o custo do capital próprio. Posteriormente, o CMPC foi determinado a partir da multiplicação do saldo devedor de cada fonte pela sua taxa de juros e posteriormente esses valores foram somados. A equação (5) foi utilizada para o cálculo do CMPC:

$$
C M P C=\sum_{i=1}^{n} W_{i} K_{i}
$$

em que:

$\mathrm{K}_{\mathrm{i}}=$ custo específico de cada fonte de financiamento;

$\mathrm{W}_{\mathrm{i}}=$ participação relativa (proporção) de cada fonte de capital no financiamento total.

O CMPC encontrado para a empresa foi utilizado para a análise do projeto, pois foi considerado que ambos apresentam o mesmo risco.

No tocante à análise de projetos pelo EVA, o primeiro passo foi a apuração das reais despesas financeiras da empresa, para isso foi determinado: o custo do capital de terceiros, o custo do capital próprio e o custo médio ponderado do capital da empresa. Foi considerado que o projeto possui o mesmo risco que a empresa, por isso o CMPC encontrado pela empresa foi utilizado para o projeto. A partir do fluxo de caixa do projeto, foi determinado o lucro líquido de cada mês e o saldo do capital mensal investido e, assim calculado o custo de capital, na determinação desses valores foi desconsiderado o custo das despesas financeiras, haja vista que aqueles valores não representavam os custos reais da empresa. Sobre o saldo de capital mensal investido foi calculado o custo de capital mensal do projeto e esse foi subtraído do lucro líquido mensal do projeto, ou seja, foram encontrados os EVAs mensais. Para apurar o EVA total do projeto foi calculado o valor presente dos EVAs mensais considerando o CMPC.

\section{RESULTADOS}

$\mathrm{Na}$ empresa Fator Construções, os projetos são precificados com base nos custos diretos e no BDI (Bonificação e Despesas Indiretas). A estimativa dos custos é auferida pelo software chamado Tabelas de Composições de Preços para Orçamentos (TCPO) que, possui bases de dados para orçamentação de obras dentro de um sistema de informações para consulta, escolha, modelagem e exportação de composição de custos.

O preço que é sugerido pela tabela é uma média de preço das despesas para a execução de cada item, ou seja, os preços têm como base os preços médios de materiais e mão de obra praticada na região do país, 
sendo o preço da mão de obra composto pelo desempenho médio dos trabalhadores de cada especialidade multiplicada pelo preço médio de salário praticado na região do país escolhida. As tabelas de preços são atualizadas anualmente com base na tabela Pini.

Sobre o valor dado pelo TCPO é adicionado o percentual de BDI, esse costuma ter seu valor máximo definido em edital especifico, caso contrário, a empresa tem que respeitar o Acórdão 325/2007 e utilizar um $\mathrm{BDI}$ menor que $30 \%$. A empresa em questão costuma trabalhar com o percentual de $29 \%$. A soma das despesas e do BDI é comparada ao preço total apresentado na planilha do edital e assim a empresa determina o percentual de desconto que ela dará em sua proposta para que essa seja igual ao valor que a empresa compôs para o projeto.

O projeto analisado foi denominado Projeto A. O preço desse projeto na licitação era de $R \$ 267.766,06$. A empresa por meio do TCPO determinou que o custo direto para executar a obra seria de $R \$ 188.993,00$. A partir desse valor calculou o BDI multiplicando o custo direto por $29 \%$, o que resultou em $R \$ 54.808,00$. Assim, a empresa encontrou o valor pelo o qual ela estaria disposta a executar a obra, apresentado na Tabela 1.

Tabela 1 - Precificação pelo Método Atual

\begin{tabular}{rrr}
\hline & Custos diretos (TCPO) & $188.993,00$ \\
$(+)$ & BDI (29\%) & $54.808,00$ \\
$(=)$ & Preço de execução do projeto & $243.801,00$ \\
\hline
\end{tabular}

Fonte: Elaborado pelos autores, 2018.

Definido o preço do projeto ela determinou o percentual de desconto que ela daria sobre o preço unitário de cada item do projeto, e esse foi de $8,95 \%$. Os percentuais do BDI que a empresa emprega é dado pelo Acórdão 325/2007 e não representa as despesas e custos indiretos gerados por um projeto dentro da empresa.

Todo projeto de execução na construção civil é dividido por atividade e essas são divididas em itens, por exemplo: fundação, alvenaria, pintura etc. A empresa elabora um cronograma de execução do projeto, considerando o tempo de execução de cada item do projeto. 0 planejamento da execução dos projetos é analisado e consolidado no cronograma físico-financeiro. Esse cronograma é elaborado pelo engenheiro que irá monitorar a execução e a qualidade do que está sendo executado na obra. Os itens que serão executados são distribuídos percentualmente entre os meses de execução de forma mais econômica possível, ou seja, otimizando a equipe.

0 cronograma físico-financeiro além de auxiliar o engenheiro no prazo e atividades que serão executadas também auxilia na estimação dos custos e receitas para todos os períodos de execução. Dessa forma, a empresa tem uma estimativa do capital que será investido ou recebido mensalmente. Com base no cronograma a empresa tem uma estimativa do seu fluxo de caixa, podendo, assim, administrá-lo.

0 método de precificação utilizado atualmente pela empresa não considera o valor do dinheiro no tempo, o que deveria ser feito já que se costuma incidir em investimentos e custos financeiros antes de receber qualquer receita, ou seja, a empresa financia parte do projeto e o custo desse financiamento não é considerado.

Além disso, pode-se considerar a utilização do BDI como um problema de precificação, já que não se sabe ao certo se ele condiz com a realidade. É importante que a empresa busque auferir seus reais custos indiretos para poder aperfeiçoar seu processo de precificação.

A análise do projeto pela empresa consiste em somar a projeção de custos diretos realizados pelo projeto ao valor rateado dos custos indiretos tendo como critério o percentual executado. 0 tempo de execução do projeto é de cinco meses, os percentuais encontram-se discriminados na Tabela 2. 
Tabela 2 - Cronograma Físico-Financeiro do Percentual Executado

\begin{tabular}{rccccc}
\hline & \multicolumn{5}{c}{ Meses } \\
\cline { 2 - 6 } & $\mathbf{1}$ & $\mathbf{2}$ & $\mathbf{3}$ & $\mathbf{4}$ & $\mathbf{5}$ \\
\cline { 2 - 6 } Percentual mensal & $13 \%$ & $18 \%$ & $30 \%$ & $21 \%$ & $18 \%$ \\
Percentual acum. & $13 \%$ & $31 \%$ & $61 \%$ & $82 \%$ & $100 \%$ \\
Valor mensal & $31.694,13$ & $43.884,18$ & $73.140,30$ & $51.198,21$ & $43.884,18$ \\
Valor acum. & $31.694,13$ & $75.578,31$ & $148.781,61$ & $199.916,82$ & $243.801,00$ \\
\hline
\end{tabular}

Fonte: Elaborado pelos autores, 2018.

O projeto foi executado dentro do período previsto, de cinco meses. O valor do BDI foi distribuído de acordo com os valores aproximados da média do mercado apresentado na Tabela 3.

Tabela 3 - Composição do BDI

\begin{tabular}{lccc}
\hline & \% em relação ao BDI & $\begin{array}{c}\text { \% em relação ao } \\
\text { valor do projeto }\end{array}$ & Valor \\
\cline { 2 - 4 } Despesas financeiras & 2,00 & 1,55 & $3.779,86$ \\
Impostos & 14,93 & 11,57 & $28.207,78$ \\
Lucro & 5,07 & 3,93 & $9.590,83$ \\
Riscos e eventuais & 2,00 & 1,55 & $3.779,86$ \\
Administração central & 5,00 & 3,88 & $9.449,65$ \\
Total: & $\mathbf{2 9 , 0 0}$ & $\mathbf{2 2 , 4 8}$ & $\mathbf{5 4 . 8 0 7 , 9 8}$ \\
\hline
\end{tabular}

Fonte: Elaborado pelos autores, 2018.

Esses percentuais considerados no BDI não representam os reais custos da empresa com os itens. As despesas financeiras consideradas no BDI são referentes a uma média dada pelo Ácordão 325/2007 e tem por objetivo o pagamento de juros e taxas à terceiros, ou seja, na atual precificação e análise utilizada pela empresa não é considerado o custo do capital próprio. Todos os valores que integram o BDI foram rateados tendo como critério a execução mensal do projeto, assim tem-se a Tabela 4.

Tabela 4 - Total Executado Mensalmente

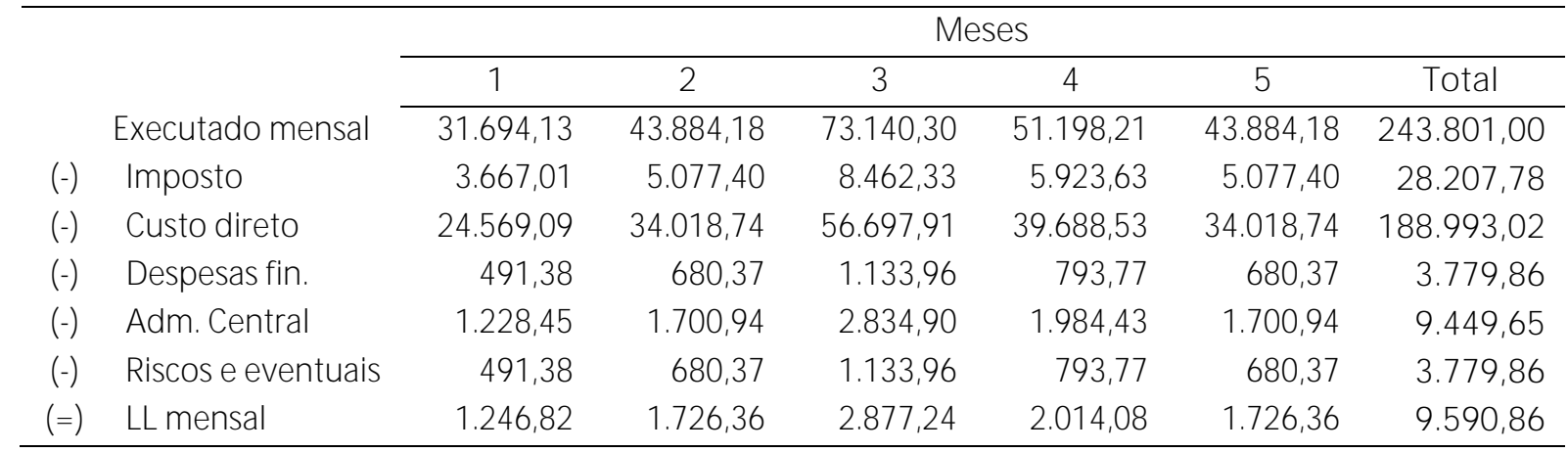

Fonte: Elaborado pelos autores, 2018.

O único valor nos custos indiretos que realmente é verdadeiro éo imposto pago, pois como a empresa é optante pelo Simples Nacional esse valor é tabelado. As empresas do setor estão cada vez mais utilizando a locação de equipamentos ao invés de comprar. A Fator Construções loca todos os equipamentos que ela utiliza na execução dos seus projetos por isso não há depreciação de equipamentos nas análises. Ao analisar o fluxo de caixa líquido do projeto pelos métodos atuais chegou-se aos seguintes resultados: o projeto gerou para a empresa um lucro de $\mathrm{R} \$ 9.590,86$; o projeto apresenta uma TIR de 2,30\% a.m. Na Tabela 5 encontra-se o fluxo de caixa do projeto. 
Tabela 5 - Fluxo de Caixa Mensal do Projeto

\begin{tabular}{|c|c|c|c|c|c|c|c|c|c|}
\hline & \multicolumn{8}{|c|}{ Meses } \\
\hline & & 1 & 2 & 3 & 4 & 5 & 6 & 7 & Total \\
\hline & Receita & & & $31.694,13$ & $43.884,18$ & $73.140,30$ & $51.198,21$ & $43.884,18$ & $243.801,00$ \\
\hline$(-)$ & Imposto & & & $3.667,01$ & $5.077,40$ & $8.462,33$ & $5.923,63$ & $5.077,40$ & $28.207,78$ \\
\hline$(-)$ & Custo direto & $24.569,09$ & $34.018,74$ & $56.697,91$ & $39.688,53$ & $34.018,74$ & & & $188.993,02$ \\
\hline$(-)$ & Despesasfin & 491,38 & 680,37 & $1.133,96$ & 793,77 & 680,37 & & & $3.779,86$ \\
\hline$(-)$ & Adm. central & $1.228,45$ & $1.700,94$ & $2.834,90$ & $1.984,43$ & $1.700,94$ & & & $9.449,65$ \\
\hline$(-)$ & $\begin{array}{l}\text { Riscos } \\
\text { eventuais }\end{array}$ & 491,38 & 680,37 & $1.133,96$ & 793,77 & 680,37 & & & $3.779,86$ \\
\hline$(=)$ & LL mensal & $(26.780,30)$ & $(37.080,42)$ & $(33.773,61)$ & $(4.453,72)$ & $27.597,55$ & $45.274,58$ & $38.806,78$ & $9.590,86$ \\
\hline
\end{tabular}

Fonte: Elaborado pelos autores, 2018.

A análise do projeto realizado hoje pela empresa não considera os reais custos de capital nem os reais custos indiretos, além de não verificar se o projeto agrega valor para a empresa. Isso pode fazer com que a ela realize uma precificação incorreta de seus projetos. A empresa precisa estudar melhores alternativas para definição de preço.

Para avaliar o projeto pelo EVA foi calculado o real custo de capital da empresa e isso foi feito em três etapas: primeiro foi realizado o cálculo do custo de capital de terceiros, segundo foi estimado o custo do capital próp rio e por último foi realizad o o cálculo do CMPC. Com as informações dos contratos de empréstimos foram montadas tabelas de amortização dos empréstimos com a finalidade de encontrar a taxa de juros e o saldo devedor de cada empréstimo, conforme a Tabela 6.

Tabela 6 - Amortização de Empréstimo

\begin{tabular}{|c|c|c|c|c|c|}
\hline \multicolumn{6}{|c|}{ Empréstimo } \\
\hline & & & & $7.666,16$ & \\
\hline & & & & 30 & \\
\hline & & & & 421,00 & \\
\hline & & & & $0,91 \%$ & \\
\hline $\mathbf{N}$ & SD & Juros & Amortização & PMT & Status \\
\hline 0 & 7.66616 & & & 421,00 & Paga \\
\hline 1 & $7.314,95$ & 69,79 & 351,21 & 421,00 & Paga \\
\hline 2 & $6.960,55$ & 66,60 & 354,40 & 421,00 & Paga \\
\hline 3 & $6.602,92$ & 63,37 & 357,63 & 421,00 & Paga \\
\hline 4 & $6.242,03$ & 60,11 & 360,89 & 421,00 & Paga \\
\hline 5 & $5.877,86$ & 56,83 & 364,17 & 421,00 & Paga \\
\hline 6 & $5.510,37$ & 53,51 & 367,49 & 421,00 & Paga \\
\hline 7 & $5.139,54$ & 50,17 & 370,83 & 421,00 & Paga \\
\hline 8 & $4.765,33$ & 46,79 & 374,21 & 421,00 & Paga \\
\hline 9 & $4.387,71$ & 43,38 & 377,62 & 421,00 & Paga \\
\hline 10 & $4.006,66$ & 39,95 & 381,05 & 421,00 & Paga \\
\hline 11 & $3.622,13$ & 36,49 & 384,52 & 421,00 & Paga \\
\hline 12 & $3.234,11$ & 32,98 & 388,02 & 421,00 & Paga \\
\hline 13 & $2.842,55$ & 29,44 & 391,56 & 421,00 & A Pagar \\
\hline 14 & $2.447,43$ & 25,88 & 395,12 & 421,00 & A Pagar \\
\hline 15 & $2.048,71$ & 22,28 & 398,72 & 421,00 & A Pagar \\
\hline 16 & $1.646,36$ & 18,65 & 402,35 & 421,00 & A Pagar \\
\hline 17 & $1.240,35$ & 14,99 & 406,01 & 421,00 & A Pagar \\
\hline 18 & 830,64 & 11,29 & 409,71 & 421,00 & A Pagar \\
\hline 19 & 417,21 & 7,56 & 413,44 & 421,00 & A Pagar \\
\hline 20 & 0,00 & 3,80 & 417,20 & 421,00 & A Pagar \\
\hline
\end{tabular}

Fonte: Elaborado pelos autores, 2018.

Foi realizada a ponderação de cada empréstimo por sua respectiva taxa de juros, o resultado consolidado pode ser visualizado na Tabela 7. 
Tabela 7 - Custo Mensal do Capital de Terceiros

\begin{tabular}{lcc}
\hline \multicolumn{1}{c}{ Banco } & Saldo Devedor & Taxa de juros \\
\hline BNDES & $134.691,74$ & $0,86 \%$ \\
BMG & $116.938,11$ & $2,55 \%$ \\
Pessoas físicas & $25.000,00$ & $2,50 \%$ \\
\hline
\end{tabular}

Fonte: Elaborado pelos autores, 2018.

O total de capital de terceiros que a empresa utiliza é de $R \$ 276.629$, sendo o custo mensal do capital de terceiros igual a $R \$ 4.759$. A taxa média de juros do capital de terceiro é de $1,72 \%$ a.m. Para o cálculo do custo do capital próprio foi utilizado o CAPM. Para a determinação do beta da empresa analisada foi calculado o beta alavancado de cada empresa do setor, que pode ser visto na Tabela 8.

Tabela 8 - Custo Mensal do Capital Próprio

\begin{tabular}{|c|c|c|c|c|c|}
\hline Empresa & $\begin{array}{c}\text { Beta } \\
\text { alavancado }\end{array}$ & $\begin{array}{l}\% \text { IRe } \\
\text { CSLL }\end{array}$ & Dívidas & PL & $\begin{array}{c}\text { Beta } \\
\text { desalavancado }\end{array}$ \\
\hline Direcional Engenharia S.A & 2,4402 & 0,34 & $2.219 .989,00$ & $1.735 .531,00$ & 1,3231 \\
\hline $\begin{array}{l}\text { Even Construtora e } \\
\text { Incorporadora S.A. }\end{array}$ & 1,7392 & 0,34 & $2.413 .652,00$ & $2.352 .000,00$ & 1,0369 \\
\hline $\begin{array}{l}\text { Ez Tec Empreend. e } \\
\text { Participações S.A. }\end{array}$ & 3,0800 & 0,34 & $999.067,00$ & $2.416 .809,00$ & 2,4198 \\
\hline Gafisa S.A & 5,1183 & 0,34 & $4.147 .449,00$ & $3.058 .403,00$ & 2,7009 \\
\hline $\begin{array}{l}\text { Helbor Empreendimentos } \\
\text { S.A. }\end{array}$ & 0,8053 & 0,34 & $3.190 .616,00$ & $1.713 .374,00$ & 0,3613 \\
\hline J HSF Participações S.A. & 11,8522 & 0,34 & $799.578,00$ & $2.276 .237,00$ & 9,6215 \\
\hline J oão Fortes Engenharia S.A. & 1,2428 & 0,34 & $1.743 .487,00$ & $851.456,00$ & 0,5286 \\
\hline $\begin{array}{l}\text { MRV Engenharia e } \\
\text { Participações S.A. }\end{array}$ & 4,5400 & 0,34 & $4.567 .642,00$ & $4.388 .008,00$ & 2,6911 \\
\hline $\begin{array}{l}\text { Rodobens Negócios } \\
\text { Imobiliários S.A. }\end{array}$ & 2,5838 & 0,34 & $275.389,00$ & $830.260,00$ & 2,1197 \\
\hline Rossi Residencial S.A. & 3,4133 & 0,34 & $4.949 .257,00$ & $1.841 .769,00$ & 1,2306 \\
\hline Tecnisa S.A. & 2,9155 & 0,34 & $3.098 .041,00$ & $1.700 .318,00$ & 1,3237 \\
\hline Trisul S.A. & 8,0530 & 0,34 & $170.998,00$ & $512.490,00$ & 6,5997 \\
\hline $\begin{array}{l}\text { Viver Incorporadora e } \\
\text { Construtora S.A. }\end{array}$ & 13,6734 & 0,34 & $995.218,00$ & $74.911,00$ & 1,3998 \\
\hline \multicolumn{5}{|c|}{ Beta Médio Desalavancado do Setor: } & 2,5660 \\
\hline & & \multicolumn{3}{|c|}{ Beta Alavancado da Empresa: } & 5,6181 \\
\hline & & \multicolumn{3}{|c|}{ Taxa livre de risco mensal: } & $0,6000 \%$ \\
\hline & & \multicolumn{3}{|c|}{ Taxa de mercado mensal: } & $1,0100 \%$ \\
\hline & & \multicolumn{3}{|c|}{ Custo do capital próprio mensal: } & $2,9032 \%$ \\
\hline
\end{tabular}

Fonte: Elaborado pelos autores, 2018.

Posteriormente, esses betas foram desalavancados, considerando a estrutura de capital das empresas e a taxa média de imposto de renda e contribuição social sobre o lucro. 0 próximo passo foi o cálculo do beta médio desalavancado do setor por meio de média aritmética simples. 0 último passo para conseguir o beta da empresa foi alavancar o beta médio desalavancado do setor considerando a estrutura de capital da empresa analisada.

Em posse do beta da empresa foi possível calcular o custo do capital próprio. A taxa do ativo livre de risco utilizada no trabalho foi o retorno médio da poupança no período de 195 meses (novembro/1998 a dezembro/2014). Os dados foram colhidos no site do Banco Central e foi considerado o vencimento no primeiro dia de cada mês. A taxa média livre de risco ao ano ficou em 7,44\%, equivalente a 0,6\% a.m. 0 retorno do mercado foi calculado levando-se em consideração o preço de fechamento ajustado do primeiro dia de cada mês e seu valor ficou em 12,81\% a.a., equivalente a 1,01\% a.m. 


$$
\begin{gathered}
\mathrm{CAPM}=R_{F}+\beta\left(R_{M}-R_{F}\right) \\
\mathrm{CAPM}=0,0060+5,62 \times(0,0101-0,0060) \\
\text { CAPM }=2,90 \% \mathrm{a} . \mathrm{m}
\end{gathered}
$$

O custo do capital próprio da empresa Fator Construções foi estimado em 2,90\% ao mês, equivalente a 40,98 \% ao ano. De posse dos dados o cálculo do custo médio ponderado do capital foi feito pela multiplicação da taxa correspondente sobre o montante de capital de cada origem, a taxa de juros do capital da empresa é de $2,22 \%$ ao mês ou $30,15 \%$ a.a.

$$
\begin{gathered}
\mathrm{CMPC}=0,0290 \times(200.000 / 476.629)+0,0172 \times(276.629 / 476.629) \\
\text { CMPC }=0,0222 \text { ou } 2,22 \% \text { a.m. }
\end{gathered}
$$

Com o CMPC determinado a análise EVA propriamente dita do projeto pôde ser realizada. Considerouse que a estrutura de capital do projeto e seu risco eram idênticos aos da empresa, por isso, o mesmo CMPC encontrado para a empresa foi empregado na análise do projeto.

Com o fluxo de caixa do projeto é possível estimar o capital que a empresa deve que investir todo mês para viabilizar a execução do projeto e para isso foi considerado o somatório das saídas desconsiderando as despesas financeiras. Por meio das estimativas, o capital que seria investido, é definido pela Tabela 9.

Tabela 9 - CMPC mensal

\begin{tabular}{cccc}
\hline Mês & $\begin{array}{c}\text { Capital investido ao } \\
\text { mês }\end{array}$ & $\begin{array}{c}\text { Saldo do capital } \\
\text { investido }\end{array}$ & CMPC (2,22\% a.m.) \\
\hline 1 & $26.288,93$ & $26.288,93$ & \\
2 & $36.400,06$ & $62.688,99$ & 578,36 \\
3 & $32.639,64$ & $95.328,63$ & $1.379,16$ \\
4 & $3.659,95$ & $98.988,58$ & $2.097,23$ \\
5 & & $70.710,67$ & $2.177,75$ \\
6 & & $25.436,09$ & $1.555,63$ \\
7 & & - & 559,59 \\
\hline
\end{tabular}

Fonte: Elaborado pelos autores, 2018.

Considerando o Projeto A, pode-se perceber que existem muitos fluxos negativos, ou seja, a empresa

\begin{tabular}{|c|c|c|c|c|c|c|c|c|}
\hline & \multicolumn{7}{|c|}{ Meses } \\
\hline & & 1 & 2 & 3 & 4 & 5 & 6 & 7 \\
\hline & Receita & & & $31.694,13$ & $43.884,18$ & $73.140,30$ & $51.198,21$ & $43.884,18$ \\
\hline$(-)$ & Imposto & & & $3.667,01$ & $5.077,40$ & $8.462,33$ & $5.923,63$ & $5.077,40$ \\
\hline$(-)$ & $\begin{array}{l}\text { Custo } \\
\text { direto }\end{array}$ & $24.569,09$ & $34.018,74$ & $56.697,91$ & $39.688,53$ & $34.018,74$ & & \\
\hline$(-)$ & CMPC & 0 & 578,36 & $1.379,16$ & $2.097,23$ & $2.177,75$ & $1.555,63$ & 559,59 \\
\hline$(-)$ & $\begin{array}{l}\text { Adm. } \\
\text { central }\end{array}$ & $1.228,45$ & $1.700,94$ & $2.834,90$ & $1.984,43$ & $1.700,94$ & & \\
\hline$(-)$ & $\begin{array}{l}\text { Riscos e } \\
\text { eventuais }\end{array}$ & 491,38 & 680,37 & $1.133,96$ & 793,77 & 680,37 & & \\
\hline$(=)$ & LL mensal & $(26.288,92)$ & $(36.978,41)$ & $(34.018,81)$ & $(5.757,18)$ & $26.100,17$ & $43.718,95$ & $38.247,19$ \\
\hline
\end{tabular}
investiu capital próprio nos meses iniciais para viabilizar a operação e esse seria o investimento mensal realizado pela empresa e esses devem ser remunerados conforme a tabela. 0 custo médio ponderado do capital é subtraído do fluxo de caixa diminuindo, assim o lucro realizado pelo projeto, conforme a Tabela 10.

Tabela 10 - Fluxo de caixa mensal considerando o CMPC 
Ao analisar um projeto que foi executado pela empresa analisada constatou-se que o custo do capital próprio foi relevante dado que pelo atual método de análise da empresa o resultado do projeto foi de $R \$$ 9.590,86, ao calcular o valor presente do fluxo considerando a taxa de desconto de CMPC encontrada tem-se que o projeto gerou $R \$ 306,43$. Porém, quando se calcula o valor presente dos EVAs mensais o resultado é $R \$$ $-3.723,86$, ou seja, esse projeto não agrega valor à empresa. 0 resultado muda drasticamente, demonstrando a importância de se considerar o real custo de capital na precificação e análise de projetos. Ou seja, a análise evidenciou a sensibilidade do resultado do projeto em relação ao custo do capital próprio.

\section{CONCLUSÕES}

O objetivo desse trabalho foi verificar se a utilização da metodologia EVA na análise e precificação de projetos agregaria informações e conhecimentos que não seriam alcançados pela empresa Fator Construções, caso a empresa optasse por metodologias mais simples, usadas atualmente pela empresa. Escolheu-se um projeto que foi executado para fazer a análise utilizada pela empresa e a análise utilizando o EVA. Por se tratar de um tema pouco explorado em pesquisas no campo de administração no Brasil, o presente estudo torna-se importante por contribuir com a literatura ainda escassa sobre o tema. Esse estudo se justificou também por buscar esclarecer e evidenciar sobre o uso da ferramenta EVA, fornecendo subsídios para gestores e pequenos empresários em ambientes de tomadas de decisões.

O resultado do trabalho mostrou que a utilização do EVA na análise e precificação do projeto aperfeiçoaria muito o método usado atualmente pela empresa por considerar o custo do capital próprio, facilitando o entendimento entre os sócios que o objetivo da empresa é a maximização do valor para eles, por meio da adequada remuneração dos capitais investidos nos projetos. A junção entre o modelo atual de precificação aliado ao EVA aperfeiçoaria o processo de precificação existente, auxiliando a empresa na escolha dos investimentos, pois ela passaria a avaliar o valor que o projeto agregaria e não apenas o total de lucro que ele geraria.

Considerando o EVA, o projeto teve seu resultado significativamente diminuído. Essa diferença evidencia a importância de se considerar o custo do capital próprio no método de precificação de um projeto, produto ou serviço pois caso esse custo seja superior ao lucro resultante da execução desse projeto o mesmo se torna inviável pois os sócios não terão como lucro nem a taxa de reto rno que almejam.

O resultado das comparações realizadas demonstra que os valores mensais do fluxo de caixa são diminuídos pelo CMPC, isso evidencia a importância de não considerar apenas os EVAs mensais. A empresa precisa considerar os EVAs mensais para verificar se a empresa suporta o valor mensal de investimentos que ela terá que realizar. Porém, ela precisa analisar o EVA total do projeto pois a análise parcial do fluxo pode indicar que o projeto realizará prejuízo, o que pode não ser verdade. 0 EVA no trabalho demonstrou-se muito eficiente pois a partir da correta remuneração de todos os investidores o fluxo de caixa do projeto se tornou mais realístico, antes o valor era estimado por um acórdão e passou a ser o valor efetivo, melhorando a base para que os sócios possam tomar decisões mais fundamentadas.

A empresa precisa se empenhar em mensurar seus custos e despesas reais com o projeto para usar uma média para realizar as precificações futuras. Pois, basear o BDI apenas pelos valores referenciais pode fazer com que a empresa não precifique corretamente seus projetos. E isso pode prejudicá-la em dois aspectos: caso ela precifique seu projeto acima do valor justo ela pode encontrar dificuldade de ganhar novas licitações e caso ela precifique abaixo do valor justo ela pode realizar prejuízos. Dada à importância da precificação para esse tipo de empresa é necessário que invistam sempre no aprimoramento das ferramentas de precificação dos projetos a fim de conseguirem um bom posicionamento no mercado e o EVA se mostrou uma ótima ferramenta de gestão para auxiliar a empresa.

No que concerne às limitações, a principal restrição desde estudo reside na estratégia de pesquisa adotada. Por se tratar de um estudo de caso, as conclusões e recomendações apresentadas, retratam apenas a realidade da empresa estudada, o que limita a dimensão, mas não a validade dos resultados encontrados. Apesar desta limitação, esta pesquisa destaca a possibilidade de realização de estudos futuros complementares sobre o EVA, corroborando ainda mais com a compreensão do tema em questão. 


\section{REFERÊNCIAS}

ASSAF NETO, A.; LIMA, F. G. Curso de administração financeira. 2. ed. São Paulo: Atlas, 2011.

BLACK, F., J ENSEN, M.; SCHOLES, M. The capital asset pricing model: some empirical Tests. In: J ENSEN, M. (Ed.). Studies in the theory of capital markets. New York: Praeger, 1972. p. 1-54.

BRASIL. Lei № 8.666, de 21 de junho de 1993. Regulamenta o Art. 37, inciso XXI, da Constituição Federal, institui normas para licitações e contratos da Administração Pública e dá outras providências. Brasília: Senado Federal, 1993. Disponível em:

http://www2.senado.leg.br/bdsf/bitstream/handle/id/531037/Lei_8666_1ed.pdf?sequence=1. Acesso em: 20 jan. 2015.

BASSAN, H.; MARTINS, R. A. Geração de riqueza em empresas vencedoras do PNQ: uma análise usando EVA. Production, v. 26, n. 1, p. 203-217, 2016.

BRUNI, A. L. Avaliação de investimentos. São Paulo: Atlas, 2008.

CASTRO J R., F. H. F.; FAMÁ, R. As novas finanças e a teoria comportamental no contexto da tomada de decisão sobre investimentos. Caderno de Pesquisas em Administração, v. 9, n. 2, p. 25-35, 2002.

CERVO, A. L.; BERVIAN, P. A.; SILVA, R. D. Metodologia científica. 6. ed. São Paulo: Pearson Prentice Hall, 2007.

CURADI, F. C. et al. Valor Econômico Agregado (EVA): um estudo na literatura vigente. Revista

Desenvolvimento Socioeconômico em Debate, v. 3 n. 1, p. 67-84, 2017.

DAMODARAM, A. Avaliação de investimentos: ferramentas e técnicas para a determinação do valor de qualquer ativo. Rio de J aneiro: Qualitymark, 1999.

GITMAN, L. J. Princípios de administração financeira. 12. ed. São Paulo: Pearson, 2010.

GIRÃO, L. F. A. P.; MACHADO, M. A. V.; CALLADO, A. L. C. Análise dos fatores que impactam o MVA das companhias abertas brasileiras: será o EVA mais value relevant que os indicadores de desempenho tradicionais? Sociedade, Contabilidade e Gestão, v. 8, n. 2, p. 89-105, 2013.

KERZNER, H. Gerenciamento de projetos: uma abordagem sistêmica para planejamento, programação e controle. 10. ed. São Paulo: Edgard Blücher, 2011.

LAPONNI, J . C. Projetos de investimento na empresa. São Paulo: Elsevier, 2007.

LINTNER, J. The valuation of risk assets and the selection of risky investments in stock portfolios and capital budgets. Review of Economics and Statistics, v. 47, n. 1, p. 13-37, 1965.

MACHADO, M. A. V.; MACHADO, M. R. Liquidez e precificação de ativos: evidências do mercado brasileiro. Brazilian Business Review, v. 11, n. 1, p. 73 - 95, 2014.

MARION, J. C. Contabilidade básica. 10. ed. São Paulo: Atlas, 2009.

MOSSIN, J. Equilibrium in a capital asset market. Econometrica, v. 34, n. 4, p. 768-783, 1966.

MARKOWITZ, H. Portfolio selection. Journal of Finance, v. 7, n. 1, p. 77-91, 1952.

RAMPAZZO, L. Metodologia científica: para alunos dos cursos de graduação e pós-graduação. 3 ed. São Paulo: Loyola, 2005.

SAMANEZ, C. P. Gestão de investimentos e geração de valor. São Paulo: Pearson, 2010. 
SEBRAE. Empreendedorismo no Brasil: relatório executivo. 2012. Disponível em: http://.sebrae.com.br. Acesso em: 12 fev. 2014.

SHARPE, W. F. Capital asset prices: a theory of market equilibrium under conditions of risk. Journal of Financial, v. 19, n. 3, p. 425-442, 1964.

YIN, R. K. Estudo de caso: planejamento e métodos. 3. ed. Porto Alegre: Bookman, 2005. 